\title{
Algumas RefleXõES SOBRE A TRADUÇÃo À LETRA SEGUNDO BERMAN
}

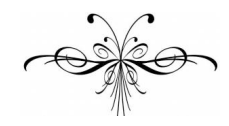

Pere Comellas

\section{A tradução literária e sua serventia}

$\mathrm{E}$ mbora nestes tempos mercantilistas (que tempos não foram?) com frequência só se considere útil aquilo que dá dinheiro, é difícil justificar a afirmação comum, às vezes feita como censura, às vezes como manifestação de profundo orgulho, de que a literatura não serve para nada. A literatura tem - e já teve seguramente mais, se não considerarmos "literatura" os grandes relatos audiovisuais - uma grande influência ${ }^{1}$ na criação de imaginários decisivos para conformar nossa visão do mundo. A estética verbal contribuiu poderosamente para criar e destruir, afiançar ou pôr em questão as nossas múltiplas identidades. Teve e tem um papel importante na conformação das nossas pátrias; trabalhou a favor e contra a opressão, o colonialismo ou a escravidão; legitimou as piores iniquidades e por vezes foi a primeira em denunciá-las.

Por isso os literatos foram (e são) perseguidos ou elevados, condenados ou exaltados segundo o grau em que os imaginários criados apoiavam ou atacavam os interesses daqueles que em cada momento têm o poder de perseguir ou de exaltar. E não só viram os seus textos proibidos, ou as suas próprias pessoas privadas de liberdade e com frequência até da vida. Também sofreram as consequências do seu próprio remédio, quer dizer, tiveram de enfrentar discursos que os desacreditavam, que tornavam aquilo que eles tinham escrito desconfiável e suspeito, ou "mau", e portanto sem lugar no cânone dos conformadores de mentalidade. Quem é que, na cultura ocidental, não imagina a Idade Média como um quadro de Walter Scott? Em que medida Umberto Eco com o seu O Nome da Rosa ou Ken Follet com Os Pilares da Terra, por citar dois autores largamente lidos, matizaram ou alteraram essa representação? É comparável a influência dessas fontes no nosso imaginário medieval com a que tiveram os artigos especializados publicados em prestigiosas revistas científicas por eruditos medievalistas? Acho que não.

Ora bem, a maior parte das pessoas não leram Eco ou Follet. Leram as suas traduções. Só pelas traduções existe de fato a possibilidade de conceber uma literatura universal (embora continue a ser, apesar de tudo, quase exclusi-

1 Para Lefevere (1992: 2), na verdade o período em que "the book occupied a central position in both the teaching and writing and the transmission of values" acabou; a cultura do livro foi substituída por uma cultura do cinema, da televisão e da música popular. 
vamente literatura ocidental). E também as traduções, como o resto da literatura, foram e são proibidas e perseguidas ou incentivadas e publicitadas. ${ }^{2}$ É claro que as traduções contribuem a conformar imaginários na mesma medida que os textos originais. Nesse sentido, portanto, a serventia da tradução literária é a mesma que a do resto da literatura.

Talvez alguém quisesse pôr em questão uma afirmação como essa. Porque de fato a tradução não criaria imaginários, mas se limitaria a difundir os imaginários criados pelas obras originais, certamente num âmbito linguístico e cultural diferente, mas com as mesmas imagens. Difundir, não alterar ou recriar. Ou seja, na mente dos leitores ingleses de Walter Scott teríamos uma representação do passado histórico europeu igual à que acharíamos na mente dos seus leitores em italiano, persa, catalão ou javanês.

Não é preciso assinalar que é essa uma concepção um tanto ingênua da tradução. ${ }^{3}$ Em palavras de Lefevere (1992: 9), "Rewriting manipulates, and it is effective", e precisamente "translation is the most obviously recognizable type of rewriting, and [...] it is potentially the most influential because it is able to project the image of an author and/or (series of) work(s) in another culture". Mais ainda: "Rewriters and translators are the people who really construct cultures on the basic level in our day and age. It is as simple, and as monumental as that. And because it is so simple and yet so monumental, it is also transparent: it tends to be overlooked" (Bassnett e Lefevere 1998: 10). A tradução, aliás, é a forma de rescrita que mais evidentemente e com maior sucesso substitui, para os leitores não académicos - isto é, para a imensa maioria - o texto original. Essa substituição pode se dar também com outras formas de rescrita (hoje talvez a mais frequente seja a adaptação cinematográfica), mas nunca é tão completa, tão inconsciente: a gente diz "vi o filme", mas conserva uma certa consciência de que não é exatamente a mesma coisa.

Assim sendo, o presente artigo pretende reflexionar sobre uma proposta tradutológica de Antoine Berman, que visa visibilizar a tradução - contra uma tendência muito presente na edição contemporânea em sentido contrário -, evidenciar o estrangeiro que há no texto traduzido.

\section{Depende}

“Como é que tal coisa se traduz?". É essa uma pergunta que nas aulas de tradução o professor tem de enfrentar com muita frequência, e felizmente (na minha opinião) a maior parte das vezes pode legitimamente responder "depende", o que, na face daqueles que acreditam que a tradução não é mais do que uma técnica, tantas vezes faz surgir uma expressão desapontada ou cética ("será que não sabe?”). Em tradução não há fórmulas fixas que resolvam os proble-

\footnotetext{
2 Em geral, os tradutores, por serem tais, não receberam o reconhecimento que sim obtiveram os autores. No entanto, receberam os mesmos castigos. Chega com lembrar a persecução dos tradutores bíblicos no século XVI, ou a dos tradutores dos Versos Satânicos no século XX.

3 Se alguém achar que uma tradução é o mesmo que o texto que traduz, só tem de comparar o título brasileiro e o título português do best-seller Flickan som lekte med elden, segunda parte da trilogia de Stieg Larsson. Em Portugal o romance foi publicado com o título A Rapariga que Sonhava com Uma Lata de Gasolina e Um Fósforo; no Brasil, com o título A Menina que Brincava com Fogo. Criam esses dois títulos a mesma imagem mental da protagonista no leitor?
} 
mas. ${ }^{4}$ No entanto, esse "depende" não é só por causa da complexidade do fenômeno traslatório nem da grande casuística de variáveis (gênero textual, iniciador, skopo, modalidade, contextos...), como também porque as nossas opções implicam escolhas éticas importantes, tanto para a própria cultura como para a cultura que tentamos traduzir.

A abordagem geral frente a uma tradução tem consequências bem profundas e bem visíveis no processo e no produto, e portanto a reflexão sobre a posição do tradutor perante o texto não é simplesmente um entretenimento de teóricos ociosos, mas um ponto de partida de grandes consequências: "Los traductores, pues, necesitan estudiar teoría de la traducción, así como historia de la traducción. Necesitan un terreno teórico e histórico que los ayude a ser flexiblemente inventivos en el desarrollo de las diferentes estrategias de traducción y conceptualmente sofisticados a la hora de evaluar su valor cultural y su función social." (Venuti 2000: 34)

Bassnett e Lefevere (1998) propõem três abordagens possíveis, três respostas à pergunta "como se traduz?": o modelo Jerônimo, o modelo Horácio e o modelo Schleiermacher. O primeiro parte da convicção de que um texto tem um referente fixo, estável, concreto, que assinala uma parcela da realidade que está lá, independente do observador. Essa realidade deve ser estabelecida (compreendida) pelo tradutor e reexprimida com os recursos de outra língua. Apesar da enorme quantidade de conceitos problemáticos que leva implícitos, provavelmente seja ainda hoje a concepção majoritária, de sentido comum, entre a população geral e até entre profissionais, embora segundo Bassnett e Lefevere (1998: 2) "the days of the Jerome model are now numbered, at least in the West". Talvez não seja este modelo - afirmam esses autores - de todo rejeitável nos textos "not considered to belong to a society's cultural capital", como um manual de instruções de uma máquina de lavar ou uma bula de remédio. Mas não nos é útil para a tradução de literatura, o nosso ponto de interesse, por quanto precisamente os textos literários constituem sobretudo capital cultural (e portanto a sua compreensão e valorização depende fundamentalmente do observador como sujeito social e histórico).

Quanto aos outros dois modelos, o Horácio e o Schleiermacher, uma interessante e influente tendência nos estudos da tradução contemporâneos, representada por especialistas tão díspares e prestigiosos como Antoine Berman, Lawrence Venuti ou os próprios Susan Bassnett e André Lefevere, ${ }^{5}$ inclinou-se para a crítica ao primeiro e a defesa do segundo. Qual é o modelo Schleiermacher? Este autor propõe, no seu Über die Verschiedenen Methoden des Übersetzens (traduzido para o espanhol como Sobre los diferentes métodos de tradu-

4 O que não implica nenhum relativismo niilista. Simplesmente, a tradução é uma atividade complexa que está sujeita a uma grande quantidade de fatores.

5 Os nossos comentários sobre a questão vão centrar-se fundamentalmente em Berman (1985), um dos pioneiros vindicadores da "estrangeiração" através do literalismo. A posição de Venuti (quem cita Berman com frequência) é bem conhecida e largamente argumentada em obras tão influentes como The Translator's Invisibility (Venuti 1995), onde se diz, por exemplo: “The point is rather to develop a theory and practice of translation that resists dominant targetlanguage cultural values so as to signify the linguistic and cultural difference of the foreign text" (23). Bassnett e Lefevere são também muito críticos com a tradição traslatória anglófona, baseada no modelo Horácio: "Translations into English, particularly from third world languages, are almost invariably slanted toward English: we are confronted with what we may term the 'Holiday Inn Syndrome', where everything foreign and exotic is standardised, to a great extent." (1998: 4) 
cir por Valentín García Yebra en 1978, versão que usamos aqui), dois caminhos: "o bien el traductor deja al escritor lo más tranquilo posible y hace que el lector vaya a su encuentro, o bien deja lo más tranquilo posible al lector y hace que vaya a su encuentro el escritor" (Schleiermacher 1813: 47). E não se trata, como poderia parecer, de dois pólos unidos por um continuum entre os que a tradução vai oscilando e situando-se, mas de duas opções excludentes: "cualquier mezcla produce necesariamente un resultado muy insatisfactorio, y es de temer que el encuentro de escritor y lector falle del todo". No primeiro caso o tradutor pretende que o resultado seja como se o autor tivesse traduzido a própria obra para a língua do leitor, de jeito que o leitor poderá sentir a estranheza de um texto estrangeiro e conservará a constante consciência de estar frente a uma tradução. No segundo, o tradutor quer que o resultado seja como se o autor tivesse escrito essa obra originalmente na língua do leitor, de forma que o leitor a vai ler sem estranheza nenhuma e nunca sentirá achar-se frente a uma tradução. Ora bem, de fato Schleiermacher, depois de apresentar as duas alternativas, inclina-se claramente pela primeira como mais adequada (pelo menos para os textos que ele considera importantes, isto é, os do conhecimento e da literatura), porque a segunda, ou seja, a procura de um texto que fosse como o que teria escrito o autor se tivesse a língua do tradutor, "conduce evidentemente a la simple imitación, o a una mezcla, todavía más chocante y confusa, de traducción e imitación, que pelotea despiadadamente al lector entre su mundo y el ajeno, entre la invención y gracia del autor y las del traductor, con lo que aquél no puede experimentar ningún placer genuino, $\mathrm{y}$ acaba, sin remedio, con vértigo y cansancio sobrados" (Schleiermacher 1813: 101). Assim, para Bassnett e Lefevere (1998: 9), "the Schleiermacher model emphasises the importance of "foreignising' translation", o que pode ser um bom ponto de partida, ja que "we need to learn more about the texts that constitute the cultural capital of other civilisations, and we need to learn more about them in ways that try to overcome, or bypass the kiss of death bestowed by acculturation through analogy" (1998: 11). É a estrangeiração a resposta? É o modelo Horácio, isto é, a domesticação, sempre o beijo da morte da aculturação?

\section{Etnocentrismo, aculturação, invisibilização}

Qual é o problema ético de traduzir segundo o modelo Horácio? Para Berman (1985), essa abordagem - que seria a tradicionalmente dominante comete três pecados: é etnocêntrica, hipertextual e platônica. Etnocêntrica porque "traz tudo à sua própria cultura, às suas normas e valores, e considera o que se encontra fora dela - o Estrangeiro - como negativo ou, no máximo, bom para ser anexado, adaptado, para aumentar a riqueza desta cultura" (Berman 1985: 28). ${ }^{6}$ Daí que pretenda "traduzir a obra estrangeira de maneira que não se 'sinta' a tradução. [...] Aqui a tradução deve fazer com que a esqueçam" (Berman 1985: 33). Hipertextual porque, para ser esquecida, "a tradução deve ser escrita numa língua normativa" (33), já que "uma obra que, em francês, não é sentida como tradução é uma obra escrita em 'bom francês', isto é, em francês clássico" (34) e para tal deixa de ser propriamente uma tradução para tornar-se uma imitação, "um pastiche, uma paródia, uma recriação livre, uma paráfrase, uma ci-

6 Citações da versão em português de Torres, Furlan e Guerini. 
tação, um comentário, ou ser uma mescla de tudo isso" (34), um hipertexto. O resultado de uma tradução hipertextual é uma falsificação, não uma reprodução: "é a diferença entre o copista e o falsário em pintura" (35). Platônica porque precisa partir da convicção de que existe "um 'sentido' considerado como um ser em si, como uma pura idealidade, como um certo 'invariante' que a tradução faz passar de uma língua a outra deixando de lado sua casca sensível, seu 'corpo"” (32). Essa tradução seria platônica porque acredita que a verdade do texto não está na letra, que só é um reflexo imperfeito, senão numa entidade autônoma, o sentido, e que é possível desencarnar esse sentido, extraí-lo da sua letra e voltá-lo a encarnar em outra letra inteiramente distinta mas de idêntica significação.

Que repercussões éticas tem essa tradução? Já estão mais ou menos enunciadas nos seus pecados: o etnocentrismo é apresentado como desprezo pelas outras culturas, que rapidamente se torna imperialismo: "como na Antigüidade o impulso evangelizador unia-se ao impulso anexionista romano, o evangelismo tradutório de Nida une-se hoje ao imperialismo cultural norteamericano" (Berman 1985: 31). A hipertextualidade é uma forma de falsificação, isto é, de roubo e de negação: apropriação das ideias de outros, ocultação da sua autoria. O platonismo é condição necessária para o etnocentrismo, pois uma tradução fundada sobre a primazia do sentido "considera implicitamente ou não sua língua como um ser intocável e superior, que o ato de traduzir não poderia perturbar" (33). O modelo Horácio é portanto desonesto com o autor do texto que traduzimos (falsifica-o), com a cultura à que pertence (a manipula), com o agente da tradução (o invisibiliza) e até com o leitor (o engana e o infantiliza, pois afinal o seu objetivo é deixá-lo tranquilo, que não precise fazer esforço nenhum).

\section{A alternativa: receber o Outro enquanto Outro}

O modelo Schleiermacher, ao contrário, seria a face oposta: "Foreignizing translation in English can be a form of resistance against ethnocentrism and racism, cultural narcissism and imperialism, in the interests of democratic geopolitical relations" (Venuti 1995: 20). Mas como fazer para estrangeirizar? Para o autor alemão, "cuanto más se ciña la traducción a los giros del original, tanto más extraña será la impresión que el lector reciba" (Schleiermacher 1813: 67). "O objetivo ético de traduzir, por se propor acolher o Estrangeiro na sua corporeidade carnal, só pode estar ligado à letra da obra" (Berman 1985: 70). Uma tradução ética será, portanto, uma tradução visível, não transparente, não fluida, estranha para o leitor por quanto visa reproduzir a estranheza que deveria supor a leitura do estrangeiro. Como conseguir essa estranheza? Permanecendo perto da letra, evitando a desencarnação e reencarnação de um suposto sentido com existência própria, reproduzindo as peculiaridades dos significantes originais.

Berman oferece exemplos dessa forma de traduzir: a versão dalguns poemas de Safo de Michel Deguy; o Sófocles de Hölderlin; o Milton de Chateaubriand; a Eneida de Klossowski. Amostras concretas, materiais, da vontade de evitar um modelo de tradução etnocêntrica, do compromisso com uma concepção da ética que exige "'recibir lo extranjero como extranjero', poner en pie un 'proceso' en el que la lengua, la literatura y la cultura de llegada admitan 
el texto extranjero en sus propias estructuras y sufran un cambio" (Venuti 2000). Trata-se simplesmente de traduzir palavra por palavra? Não, isso seria quase sempre impossível, absolutamente incompreensível, pelo menos entre línguas geneticamente afastadas como grego e alemão ou tipologicamente diferenciadas como latim e francês. Se estrangeirizar fosse só decalcar o original, com certeza o resultado de um tal modelo traslatório ia ser ainda mais arriscado e rejeitado do que já são em geral as traduções consideradas estrangeirizantes. Que significa então na prática ser literal no sentido de permanecer perto da letra?

\section{Traduzir à letra}

Por exemplo, na tradução do latim para o francês, línguas com uma sintaxe muito diferente, não seria possível reproduzir à risca a ordem de palavras do original sem criar um texto absurdo em francês. Para Berman, aqui traduzir perto da letra significa conseguir que a ordem palavra-por-palavra seja "aparente". Klossowski traduz a Eneida para um francês latinizado, mas "essa latinização se efetua sem ser um calco, sem violentar gratuitamente (como a pura 'palavra-por-palavra') a nossa língua. De fato, trata-se de implantar em francês o caráter 'fragmentado' da sintaxe latina, de introduzir as rejeições, as inversões, os deslocamentos etc. do latim que permitem o jogo de palavras no dizer épico, mas sem por isso reproduzir ingênua e servilmente rejeições, inversões e deslocamentos do original; sem copiá-los 'tais quais'. A diferença é considerável: o que é 'traduzido' é o sistema global das inversões, rejeições, deslocamentos, e não suas distribuições factuais ao longo dos versos da Eneida" (Berman 1985: 121).

Ora bem, tem a sintaxe do latim um caráter fragmentado? Sim, do ponto de vista de uma língua como o francês, com uma ordem de palavras muito mais fixa, cujos falantes sentem como "inversões, rejeições, deslocamentos" certas expressões só porque não respeitam a ordem "normal". É como dizer - o que com frequência se diz - que os árabes escrevem "ao invés" só porque estamos habituados à ordem esquerda-direita, tão arbitrária e convencional como a contrária. Não é isto também etnocentrismo?

Vejamos um pormenor da tradução do fragmento 140 de Safo para o francês, que Berman coloca também como exemplar. Deguy traduz a série de comparações do poema na mesma ordem que usa o grego ("que leite mais branca" e não o "normal" em línguas românicas "mais branca que o leite"), só que também introduz um ponto de interrogação e uma separação tipográfica depois do termo de comparação, talvez para evitar a ambiguidade: "Que lait? plus blanche". Berman (1985: 75) afirma que na ordem habitual "as comparações são traduzidas, mas não sua imediatez, seu frescor de comparações". Mas como "medir" a imediatez, o frescor? Além disso, Berman afirma que "esta acentuação por interrogação não é arbitrária, pois corresponde a uma certa ligação sáfica da interrogação com a comparação [...]. É o laço imemorial - pensem nos poemas célticos irlandeses - entre questionamento e comparação. A acentuação sublinha no original o que já está ali de forma latente" (Berman 1985: 77). Então os poemas célticos e o conhecimento de outras tradições explicitam o que no original é latente e legitimam esse uso na tradução. Mas não é isso também intertextualidade? 
Mais ainda: a ideia de que no poema de Safo está latente a existência do laço entre questionamento e comparação não indicaria que existem sentidos desligados da letra? Não é esse o platonismo que o autor acha rejeitável? Berman insiste: "De certo modo, a tradução produziu um texto mais desconcertante que o de Safo, mas este desconcerto já existia, oculto, na poesia. Pode-se dizer que ela voltou à origem do original" (Berman 1985: 77), e a seguir cita um fragmento de Alain onde se diz que uma certa tradução de Shelley é "mais inglês que o inglês, mais grego que o grego, mais latim que o latim". Mas então há um ser grego, uma essência grega desligada das palavras gregas e que pode emergir numa tradução para outra língua? Não é essa uma visão platônica das línguas? Não indica, por outro lado, uma forma muito francesa de manter-se perto da letra, que não seria útil em traduções para outras línguas?

Um dos problemas para quem quiser seguir as propostas de Berman é que muitos dos comentários críticos sobre as opções traslatórias que ele faz podem considerar-se impressionísticos. Se a ordem de palavras é seguida ou alterada ou se um adjetivo é anteposto ou posposto é inquestionável. Ora bem, se uma determinada solução "banaliza" o texto, ou se uma certa língua fica mais "pura", ou "velha e gasta" ou então "rejuvenescida" é muito menos evidente. Como medir a pureza ou o grau de banalidade de um texto? Como caracterizar uma língua? Podem ser as línguas "velhas", "puras" ou "selvagens"? Não será isto uma reificação, a construção de um objeto "língua" definido metaforicamente com qualidades materiais, sensíveis, segundo o velho modelo romântico? Afirma Berman (1985: 131) que com as propostas de Klossowski "a língua materna, longe de se alienar, acede a camadas insuspeitas do seu ser". Portanto a língua tem uma essência desligada (pelo menos até certo ponto, já que essa essência pode permanecer oculta, insuspeita nas formas atuais da língua) da sua materialidade, uma essência pré-existente e que até pode não chegar a revelar-se (se não tiver um tradutor como Klossowski). Mais um ponto de vista platônico e não falsável usado com frequência para situar umas línguas por cima de outras, hierarquizá-las segundo capacidades (maior aptidão para certos usos, maior "riqueza", maior "precisão"...) ou segundo graus evolutivos (mais "primitivas", mais "primárias", menos "evoluídas"...) que, pela evidência empírica que a linguística foi capaz de fornecer até agora, parecem simples preconceitos etnocêntricos. Berman (1985: 58-59), por exemplo, fala do papel das "línguas vernaculares" em oposição as coinés ou línguas cultas. Vernacular seria, no texto, qualquer variedade não padrão, mas curiosamente (ou talvez nem tanto) exemplifica essa categoria com o gascão, com o dialeto da Picardia, com o antigo francês, com o antilhano, com a gíria de Paris e com o falar normando. E ainda com uma categoria mais geral, a "oralidade vernacular". Um lista no mínimo heteróclita. Certo, não há forma rigorosa de estabelecer o que é uma língua (sempre é bom lembrar aquela famosa máxima atribuída a Max Weinreich segundo a qual uma língua é um dialeto com exército e marinha). O problema aqui é que implicitamente Berman situa em dois planos distintos as "línguas cultas" e as "vernáculas", e lhes atribui diferenças essenciais: "a língua vernacular é por essência mais corporal, mais icônica que a coiné, a língua culta" (58). O que é uma língua "icônica"? Pode existir uma morfologia, uma sintaxe icônicas? Ou será que a iconicidade só se encontra no léxico? Exemplos de Berman: "No dialeto da Picardia, 'biblioteux' é mais falado do que o francês 'livresque'. O antigo francês 'sorcelage', mais rico que 'sorcellerie', o antilhano 'dérespecter', mais dire- 
to que o francês "manquer de respect"' (58). Novamente a mesma questão impressionística: como medir a corporeidade e a iconicidade de biblioteux ou de sorcelage?

Depois Berman critica o apagamento da "oralidade vernacular" nas traduções, e a exemplifica com a tradução de porteño por "habitant de Buenos Aires”. Mas é a palavra porteño vernacular em oposição a culto? É oral? Por quê? No corpus do espanhol atual da Real Academia de la Lengua Española aparece profusamente, sobretudo em documentos da imprensa argentina, mas também em jornais ou livros espanhois, mexicanos, etc. Até em contextos do âmbito das ciências e da tecnologia. É o gentílico mais habitual de Buenos Aires em todo tipo de contextos linguísticos, até os mais padronizados. Será que a vernacularidade de porteño é só produto de um olhar etnocêntrico?

\section{Afinal, nem tão perto}

Certamente, as traduções mostradas por Berman atingem o objetivo de estrangeirizar os textos, de evitar a invisibilidade da tradução à procura da fluência a qualquer preço. Não fica tão claro, no entanto, que consigam isso através de uma tradução à letra. De fato, com frequência as traduções exemplares que Berman mostra fogem radicalmente dela. ${ }^{7}$ Berman propõe uma literalidade que "não reproduz a facticidade do original, mas a lógica que preside a organização desta facticidade" ali onde "a língua para a que se traduz o permite" (Berman 1985: 131). A literalidade precisa se submeter aos limites da língua meta. Mas então é muito difícil distinguir, na análise microtextual de uma tradução, o que é traduzir perto da letra e o que é domesticar, se não é que consideramos como critério a estranheza: o "estranho" é literalidade que não decalca, enquanto o "normal" é domesticação. Assim sendo, afinal o que importa não é a letra, mas a criação de estranheza, a vontade da tradução de lembrar-nos que o Outro é Outro, estrangeiro. O verdadeiro fim do modelo Schleiermacher segundo Berman seria esse, e a tradução literal só seria um dos recursos possíveis para atingi-lo, mas não o único válido.

Talvez o problema seja que a tradução à letra não é possível. O próprio Berman enfrenta esse paradoxo: sua proposta exige aproximar-se da letra, do significante, porque acha que não é lícito dissociar letra e sentido, mas no limite isso conduz à impossibilidade de traduzir: "Se letra e sentido estão ligados, a tradução é uma traição e uma impossibilidade" (Berman 1985: 40). Portanto, aí onde letra e sentido têm uma ligação mais clara a tradução é mais improvável: "Dizer que um poema é intraduzível é, no fundo, dizer que é um 'verdadeiro' poema" (40). Estamos em um beco sem saída?

\section{Língua, pensamento e referência}

Talvez sim, se ficarmos no dualismo saussuriano de significantesignificado. Mas é que falta um elemento intermediário fundamental. Uma pro-

7 Por exemplo, no apartado "As modificações" do comentário da tradução de Hölderlin (Berman 1985: 87) vemos como o tradutor substituiu sistematicamente os nomes dos deuses antigos por epítetos: Zeus vira o Pai da Terra, Afrodite a divina Beleza... 
dução verbal (uma palavra, um sintagma, uma oração...) aponta não diretamente para um referente na realidade, mas para uma representação de uma classe de referentes, para um conceito. Esse conceito, com sua etiqueta lexical, é que aponta para referências na (suposta) realidade. Temos portanto três níveis: referente real (qualquer coisa da "realidade"), categoria (a representação, o conceito) e etiqueta verbal (os sons da palavra). Quando dizemos que o signo linguístico é arbitrário queremos indicar que esses sons têm uma relação convencional com o conceito, apoiada por uma comunidade linguística e que pode mudar e de fato muda ao longo do tempo e do espaço. ${ }^{8}$ Fora da função poética da linguagem (a qual permeia qualquer produção verbal, mas é focalizada especificamente na literatura), o que interessa não é tanto a relação entre signo e conceito, como entre conceito e referente. Porque os três níveis estão evidentemente conectados, mas ao mesmo tempo têm um certo grau de autonomia (Bickerton 1990: cap. 2). Isso significa que, se a ordem semiótica natural foi alguma vez percepção > categorização > etiquetagem (isto é, a partir de um fenômeno percebido construímos um conceito, uma representação mental desse fenômeno que o classificava, e lhe demos um nome), a linguagem humana como a conhecemos agora (qualquer variedade dela, e desde muito antes da invenção da escrita) já se libertou da dependência perceptiva e pode criar categorias sem precisar de percepção nenhuma (os unicórnios ou a felicidade). De fato, o universo da representação deve manter um contato com a realidade para não deixar de ser funcional, mas dentro desse limite pode seguir seu próprio caminho. ${ }^{9}$ A discussão aqui é dupla: por um lado, até que ponto a autonomia do signo e do conceito com respeito à realidade depende da nossa vontade e da nossa consciência?; por outro lado, que profundidade tem a variação (entre signos, entre conceitos)? É algo substancial ou simplesmente aspectos superficiais? Sabemos que as línguas mudam (e portanto diferem) até o ponto de tornar-se não só totalmente incompreensíveis como também bastante diferentes em termos de organização, e no entanto as hipóteses que postulam a dependência genética da faculdade da linguagem e a essencial unidade sob a aparente diversidade provavelmente sejam as mais aceites hoje. Sabemos também que os conceitos experimentam uma certa variação em função do grupo humano, que nem todas as culturas desenvolvem exatamente as mesmas categorias sobre o mundo, mas também que poderiam existir universais de categorização.

Se decidirmos que as diferenças culturais na categorização são de grande importância, profundamente particulares, consideraremos a relação entre culturas de uma forma bem distinta da que se acreditarmos que basicamente essas diferenças são superficiais e irrelevantes. Se pensarmos que a diferente conceitualização que herdamos culturalmente condiciona nossa percepção do mundo, então acreditaremos no determinismo whorfiano; se não, aderiremos aos críticos como Steven Pinker, quem afirmou que "el sentido común acierta cuando nos dice que el pensamiento y el lenguaje son cosas diferentes, y [...] que el determinismo lingüístico es una idea completamente absurda" (Pinker 1994: 70).

8 Falamos em sons, mas nem precisam sê-lo. Nas línguas de sinais são movimentos, com idêntico funcionamento.

9 Condicionado sempre, é claro, pela realidade biológica e física que é sermos huma-nos, uma espécie extremamente homogênea. 
E a tradução? Bom, se estivermos convencidos da profunda unidade dos três níveis e da impossibilidade de desligá-los, então teremos a tradução por impossível. Mas se repararmos que, além da imprescindível ligação, apresentam uma certa autonomia, então poderemos aceitar a existência de um sentido mais ou menos independente do signo, sem por isso ter uma visão platônica. Do mesmo jeito, se acreditarmos que sob a aparência de uma extrema diversidade existe uma sólida unidade da natureza humana (e que, portanto, os elementos comuns são muito mais importantes do que os condicionantes culturais) e atribuirmos a autonomia da categorização nem tanto às especificidades culturais como às especificidades da mente humana, então consideraremos a tradução totalmente provável, com um único e pequeno obstáculo: ultrapassar essas diferenças culturais que são a diversidade de signos e a diversidade de categorias, no fundo bem superficiais sob as que subjaz uma experiência humana comum e totalmente compartilhável. ${ }^{10}$

Talvez o problema aqui seja que a cultura francófona tem uma antiga tradição no que diz respeito a tentar justificar o estatuto dominante do francês com argumentos de tipo formal. Pelo menos desde o Renascimento tem-se alimentado um mito de clareza e ordem natural relacionado com a língua. Voltaire escreve na Encyclopedie: "Le génie de cette langue est la clarté \& l'ordre. [...] Le françois n'ayant point de déclinaisons, \& étant toujours asservi aux articles, ne peut adopter les inversions greques \& latines; il oblige les mots à s'arranger dans l'ordre naturel des idées". Ainda hoje o mito continua a ser difundido inclusive por professores de língua francesa, com frequência disfarçado, como já fazia Voltaire, ${ }^{11}$ com argumentos supostamente objetivos, relacionados com a descrição gramatical. No entanto, parece claro que a naturalidade caracteriza, para todo e qualquer falante, a própria fala. Naturalidade correlativa à estranheza que causam as formas das outras.

\section{We, the Alien}

O título do conhecido manual de antropologia cultural de Paul Bohannan põe em evidência por contraste justamente o etnocentrismo tradicional da disciplina, que foi utilizada para justificar, através da caracterização das outras culturas em termos hierárquicos, a legitimidade da colonização e do domínio.

Mas é que o próprio relativismo cultural, nascido precisamente como reação à depreciação das outras culturas e com o objetivo de combater o etnocentrismo, com frequência contribuiu a difundir certos preconceitos precisamente porque enquanto tentava reivindicar o direito à diferença, tendeu a sublinhar e a sacralizar o "estranho", o "exótico". As diferenças na gramática das línguas também foram usadas para explicar supostas diferenças essenciais na mente dos indivíduos de certos povos, ${ }^{12}$ o que, até quando era para mostrar uma suposta

10 Que as diferenças linguísticas e culturais possam considerar-se superficiais não significa que não tenham um caráter fundamental na consciência coletiva e na identidade; como também não significa que não tenham valor ou que não valha a pena de serem preservadas. Mas essa já é outra história.

11 É preciso reconhecer que Voltaire (e outros autores anteriores como Bellay) ainda escreve sobre o francês com uma certa sensação de inferioridade, e por isso procura supostas vantagens no francês mas também reconhece desvantagens que não teriam outras línguas.

12 É muito conhecida a absurda ideia de que certos povos africanos viveriam num eterno 
superioridade dessas culturas com respeito à "nossa", acabava por justificar uma hierarquia cultural. Muitos dos mitos do orientalismo contemporâneo têm essa origem. Assim, o próprio amor pela diversidade cultural e um alto sentido crítico para a própria cultura acabam por contribuir à construção de um Outro irredutível, longínquo, objeto de uma admiração ingênua (como é inatingível para nós a requintada espiritualidade oriental...) ou então de uma comiseração paternalista politicamente correta (coitados, os índios, com sua estranha cultura tão próxima da natureza...). É essa a perspectiva à que se opõe ferozmente o ponto de vista universalista: "La antropología de este siglo nos enseña un variado muestrario de diferencias humanas. ¿Cabría, no obstante, la posibilidad de que este abigarrado carnaval de tabúes, sistemas de parentesco, chamanismo y otras prácticas fuera tan superficial como lo es la diferencia entre dog y perro, bajo la cual late una naturaleza humana universal?" (Pinker 1995: 453). Um ponto de vista que permite uma identificação muito maior como o Outro, que só é uma versão superficialmente distinta de Nós. O estranho torna-se familiar.

A tradução, como a antropologia cultural, já deu também sua contribuição ao colonialismo e ao racismo, como muitos estudos já evidenciaram. De fato, a tradição domesticadora, que visa sobretudo obter textos fluentes e ocultar a origem estrangeira, merece sem dúvida todas as críticas que Berman, Venuti e tantos outros lhe dirigiram. O problema é: será que a tradução, como a antropologia cultural, fugindo do fogo caiu nas brasas?

\section{Estrangeirizar ou exotizar?}

Vimos que Berman apresenta a estrangeiração como o resultado de reconhecer e receber o Outro enquanto Outro. Nos textos isso significa estrangeirizar, isto é, criar no leitor um sentido de estranheza. A ideia lembra-me o "recurso do sotaque". Na televisão espanhola, ${ }^{13}$ com uma grande tradição de dublagem, os filmes anglofalados, nos que apareciam "estrangeiros", isto é, falantes de línguas diferentes do inglês (dezenas de filmes sobre a Segunda Guerra Mundial, por exemplo), eram dublados ao espanhol mas com um forte sotaque. Assim, os oficiais alemães falavam em espanhol mas com os erres muito carregados e outras marcas fonéticas (e nos casos mais paródicos usavam de vez em quando alguma palavra alemã como Herr ou $J a$ ), o que visava criar no espectador a impressão de que de fato estavam a falar em alemão, só que compreensível.

O problema do recurso do sotaque é que não é simplesmente um modo de marcar o estrangeiro, de chamar a atenção para o fato de ele falar outra língua. A marca de estranhamento incorpora inevitavelmente um matiz despectivo. $\mathrm{O}$ estrangeiro tem sotaque, isto é, fala mal. Reparamos no modo em que fala tanto ou mais do que no que diz, parece-nos distante, diferente, Outro, mas não num sentido positivo nem sequer neutro. O sotaque exotiza, isto é, sublinha artificialmente a sua exterioridade, cria uma outridade artificial, inexistente, já que estamos a ver, por exemplo, uma conversa entre dois alemães que acontece em

presente porque na sua língua os verbos não incorporam marcas morfológicas específicas para o futuro. Esses são os perigos de considerar que língua e pensamento são a mesma coisa.

13 Imagino que seja um recurso geral na dublagem de filmes. Pelo menos a televisão catalã, mais recente, incorporou também a técnica. 
Berlim. O sotaque transmite a impressão de que tudo quanto acontece entre estrangeiros e no estrangeiro é estranho, anômalo: eles não são como nós.

A exotização de um texto através da tradução é uma consequência perigosa da estrangeirização, na minha opinião difícil de evitar. Para Ovidi Carbonell, "El exotismo es una de las formas del extrañamiento", que pode manifestar-se exatamente através das principais recomendações de tradução que dá Berman: "en la imitación de la organización textual de la lengua de origen, de sus estructuras sintácticas o en el calco semántico de algunas de sus locuciones o frases hechas". O problema é que sob o exotismo "puede esconderse no tanto un acercamiento a la cultura de origen como una recreación de la realidad ajena" (Carbonell 1997: 64). Uma recriação que salienta tudo aquilo que favorece o estereótipo exótico. Nem sequer é preciso inventar no texto traduzido elementos exotizantes supostamente existentes na cultura desse texto. Com frequência, simplesmente decalcando certos elementos já é possível reforçar o imaginário estereotipado prévio. Assim, Carbonell cita o exemplo da norma estilística do árabe de exprimir um conceito por meio de dois sinônimos, o que traduzido literalmente provoca "un efecto de imprecisión conceptual acompañado de un manierismo verbal que no corresponde al efecto del texto de salida ya que en éste sólo se está siguiendo una norma estilística extendida" (Peña e Hernández 1994: 33, citado em Carbonell 1997: 71). Isto é, a norma e o hábito de usá-la normalizam o efeito, que passa desapercebido para o leitor árabe e no entanto chama a atenção do leitor não árabe, reforçando nele a expectativa que tem do árabe: "la creencia de que la literatura oriental tendía hacia la metáfora recargada y la expresión ampulosa" (Carbonell 1997: 69).

De fato, o próprio Berman adverte sobre a prática da exotização nas traduções. O que aqui queremos salientar é a frequente possibilidade de exotizar só por meio da tradução literal, como no caso anterior, ou o de traduzir expressões do quotidiano que em outra língua tornam-se extremamente estranhas. ${ }^{14}$ Outro exemplo, os empréstimos injustificados: palavras que parecem "exóticas" são deixadas no texto traduzido na língua de partida, marcadas de alguma forma (com a tipografia ou com uma nota de rodapé). Assim, na tradução para o espanhol de Mayombe, romance do angolano Pepetela, termos tão comuns e pouco exóticos em português como "bunda" ou "catana" são deixados na tradução e esclarecidos em nota, o que "africaniza" o texto (Comellas 2005).

\section{Tudo depende das culturas que entram no jogo}

Em outro texto mais recente, Carbonell insiste na ideia de que domesticar ou estrangeirizar não são posições eticamente ou politicamente fixas. Mais uma vez, depende: "É claro que haverá teóricos que, seguindo Venuti e outros, nos dirão que familiarizar um texto significa aproximarmo-nos demasiadamente a uma assimilação do texto na cultura receptora. Como já disse em outras oca-

14 Em catalão usam-se palavrões no quotidiano que em português ganhariam um sentido muito mais chocante e ofensivo, se traduzidos literalmente. Também usamos a palavra "homem" como vocativo inclusive para mulheres; à pergunta "isto está bem?" podemos responder para uma mulher: "homem, não sei, depende" (em espanhol até se usa "macho" do mesmo jeito). Uma tradução literal recupera para a palavra um significado da que já se esvaziou completamente e vem a reforçar o estereótipo do machismo ibérico. 
siões, estranhar pode ser um recurso ideológico tão sedutor como a familiarização. Tudo depende de quais são as culturas que entram no jogo" (Carbonell 2003: 50).

A ideia de que determinadas opções de tradução (e de produção discursiva em geral) podem ser consideradas pouco éticas ou pelo menos suspeitas de desprezo para outras culturas em certos contextos linguísticos e perfeitamente aceitáveis ou até subversivas em outros é já clássica. Como disse Spivak (1995: 376), "What seems resistant in the space of English may be reactionary in the space of the original language", e vice-versa, claro. A transformação que as $R u$ baiyat de Omar Khayyam sofrem nas mãos de Edward Fitzgerald considera-se colonialista, não só pelos seus comentários explícitos ${ }^{15}$ pouco apreciativos para a poesia persa, como também pelo fato de ele ser inglês nas circunstâncias políticas do século xix. As mesmas "liberdades" que Fitzgerald se toma com Khayyam podem considerar-se em outro contexto práticas traslatórias subversivas e até anticolonialistas. Sobre as Rubaiyat, Bassnett (2002: 75) afirma que "Fitzgerald no tenía reparos en canibalizar el original". Ora bem, na classificação de Edwin Gentzler (2008), a tradução antropofágica aparece como uma das estratégias de resistência em tradução. Com efeito, essa era a posição manifesta de Haroldo de Campos: irreverente, subversiva, transgressora. Ao mesmo tempo, Gentzler cita também a estrangeirização entre as práticas resistentes, embora com um olhar crítico e cético: para ele "No all of his examples [de Venuti] are entirely convincing", e de fato "Yet evidence is increasingly showing that neither foreignization nor domestication in and of itself automatically is resistant" (Gentzler 2008: 170). Também para este autor, "Before judging and prescribing, scholars need to look specifically at who is resisting and why" (Gentzler 2008: 169).

Em outro texto considerei a legitimidade da antropofagia como prática traslatória de uma cultura como a brasileira (Comellas 2004). O que aqui interessa é salientar os problemas que a abordagem estrangeirizadora de Berman apresenta como orientação e como prática para uma tradução respeitosa com a diversidade cultural. Não se trata de defender a domesticação em si, mas de considerar a importância ética, em qualquer prática textual, do quem e do para quem.

\section{Conclusões}

Não há dúvida de que do contexto cultural de que falam Berman e o resto de críticos da prática domesticadora e da obsessão pela fluidez (francófono, anglófono...), com frequência a apropriação de textos e a invisibilização da tradução têm sido atitudes desrespeitadoras e abusivas para com outras culturas, sintoma do enorme etnocentrismo dessas sociedades. Ora bem, a alternativa da estrangeirização apresenta também problemas importantes, pelo menos na formulação desse autor. Se para ele as traduções domesticadoras "conduziram à condenação da tradução" (Berman 1985: 28), do nosso ponto de vista a prática que ele propõe de traduzir à letra ("nem calco nem [problemática] reprodução,

15 "It is un amusement for me to take what liberties I like with these Persian who (as I think) are not poets enough to frighten one from such excursions, and who really do want a little art to shape them". Citado por Lefevere 1992: 75). 
mas atenção voltada para o jogo dos significantes" [Berman 1985: 16]) a coloca à beira do perigo da exotização.

Em primeiro lugar, a estrangeirização em Berman é descrita de uma forma que permite práticas contraditórias sob o pretexto de evitar a "tradução servil", a tradução palavra-por-palavra, que além de tudo é impossível na maior parte dos textos. Tentamos mostrar como é discutível que algumas das amostras oferecidas como exemplares sejam exemplos de tradução à letra. Vimos que o critério fundamental das soluções propostas não era tanto a letra, o significante, como o estranhamento, a introdução no texto traduzido da suposta estranheza presente no Outro. ${ }^{16}$ Tratar-se-ia de construir com a tradução o "albergue do longínquo", e não de assimilar o estrangeiro: daí que precisemos sentir que é estrangeiro. Ora bem, o problema dessa posição é que tendemos a reduzir o estrangeiro ao seu estereótipo, precisamente porque esse estereótipo está formado pelo que mais nos estranha. E ao mesmo tempo o encerramos nessa estranheza, o condenamos a ser sempre Outro. Mais ainda: uma vez estabelecido, o estereótipo, como representação que é, como conceito, ganha também autonomia, de jeito que é reproduzido e recriado cada vez mais longe e de forma mais independente da realidade que supostamente representa. O que cria uma expectativa que as posteriores traduções sentem que devem satisfazer.

Portanto o estranhamento pode não ser mais do que uma exotização: a confirmação para os leitores de suas expectativas quanto às culturas estrangeiras. Assim, procuramos no árabe sempre o serralho ou o fanatismo religioso; no chinês, a espiritualidade oriental ou o perigo amarelo, e no brasileiro o jeitinho ou a violência urbana. Estranhar pode ser obrigar-nos a não ver nunca o Outro como o Igual.

Em segundo lugar, Berman, na nossa opinião, defende por vezes suas opções com julgamentos impressivos, não falsáveis. E mantém certas visões sobre as línguas e sobre a relação entre linguagem e pensamento próximas do etnocentrismo que denuncia (a noção de língua culta e línguas vernáculas, um certo determinismo ligado à relação entre signo e significado...). A ética do respeito pela diversidade cultural obriga a pôr em questão a hierarquização linguística, que afinal não é mais do que um aspecto do pensamento colonialista.

Finalmente, consideramos que domesticar ou estrangeirizar são opções legítimas ou ilegítimas em tradução em função das circunstâncias nas quais esta se produz. Particularmente, as línguas (ou falas ou variantes ou vernáculos ou como quer que queiramos chamá-las) numa situação sociolinguística não imperialista, aquelas que não foram agente de substituição, têm mais direito de canibalizar os textos, de apropriar-se de tradições longínquas, de degluti-las e digerilas ao seu gosto. As línguas imperialistas devem observar, sem dúvida, preceitos mais estritos.

O estrangeiro tem o direito de multiplicar as suas identidades: com frequência é por isso que viaja. Assimilá-lo como preço do seu deslocamento é injusto e indigno; mantê-lo no seu espaço de estrangeiro para sempre, também. Também aqui são as pequenas culturas as que podem aportar um modelo dife-

16 Seria injusto dizer que Berman pretende que seja preciso reproduzir a estranheza do texto fonte. Tal estranheza, é claro, não existe como tal, mas só para o leitor estrangeiro. Por isso afirma que "toda grande tradução se diferencia pela sua riqueza neológica, mesmo quando o original não possui nenhuma" (Berman 1985: 101), o que é uma ideia extremamente interessante. 
rente, um terceiro caminho em que para o estrangeiro adotar traços locais seja valorizar mais ainda os seus próprios traços locais, em que assumir novas identidades não seja em troca da renúncia à própria identidade, mas um elemento de reforço das identidades iniciais.

Contra o falso universalismo assimilacionista (que oculta o "estranho" porque o identifica com o perigoso ou o inferior), contra o estranhamento exotizador (que condena ao gueto tudo quanto é diferente), devemos encontrar uma abordagem da tradução complexa, enriquecedora para a cultura tradutora, uma tradução realmente universalista porque localista, que não perca nunca a consciência de que só porque somos tão extremamente iguais é importante que continuemos a ser diferentes.

Pere Comellas perecomellas@ub.edu Universitat de Barcelona 


\section{Referências bibliográficas}

BASSNETT, S. (2002). "La traducción como remembranza". Em: Álvarez, R. (ed.). Cartografías de la traducción: del post-estructuralismo al multiculturalismo. Salamanca: Almar, p. 59-76.

Bassnett, S.; Lefevere, A. (1998). "Where are we in Translation Studies?". Em: Constructing Cultures: Essays on Literary Translation. Clevedon: Multilingual Matters, p. 1-11.

Berman, A. (1985). A tradução e a Letra ou o Albergue do Longínquo. Rio de Janeiro: 7 Letras; PGET, 2007 (trad. de Marie-Hélène Catherine Torres, Mauri Furlan e Andréia Guerini).

BiCKerton, D. (1990). Lenguaje y especies. Madrid: Alianza, 1994 (trad. de M. A. Valladares Álvarez).

Carbonell, O. (1997). Traducir al otro: traducción, exotismo, poscolonialismo. Cuenca: Ediciones de la Universidad de Castilla-La Mancha.

CARbonell, O. (2003). "Com o coração à larga: sociolinguística da tradução exótica”. Scientia Traductionis, 7 (2010), p. 43-60 [disponível em: http://www.periodicos.ufsc.br/index.php/scientia/issue/view/1407]

COMEllas, P. (2004). "El derecho a la antropofagia: algunas reflexiones en torno a la ética de la traducción". Em: Camps, A. (ed.). Ética y política de la traducción en la época contemporánea. Barcelona: PPU, p. 85-94.

Comellas, P. (2005). "Línguas próximas, culturas longínquas: a tradução de Mayombe, de Pepetela, do português para o espanhol”. Revista Galega de Filoloxía, 6, p. 159-168.

GentzLER, E. (2008). "Translation and micropolitics in the age of globalization". Em: Camps, A.; Zybatow, L. Traducción e interculturalidad. Frankfurt: Peter Lang, p. 165-181.

LefeVere, A. (1992). Translation, Rewriting, and the Manipulation of Literary Fame. Londres: Routledge.

PeÑA, S.; Hernández, M. J. (1994). Traductodología. Málaga: Universidad de Málaga.

PInKer, S. (1994). El instinto del lenguaje. Madrid: Alianza (trad. de J. M. Igoa González).

SCHLEIERMACHER, F. (1813). Sobre los diferentes métodos de traducir. Madrid: Gredos, 2000 (trad. de V. García Yebra).

SpIVAK, G. (1995). "The Politics of Translation". Em: L. Venuti (2000). The Translation Studies Reader. Londres: Routledge, p. 179-200.

VENUTI, L. (1995). The Translator's Invisibility: A history of translation. London: Routledge.

VENUTI, L. (2000). “¿Será útil la teoría de la traducción para los traductores?”. Vasos Comunicantes, no 16, p. 26-35 (trad. de J. G. López Guix). 